\title{
Towards a Technology Enhanced Interaction Framework
}

\author{
K. Angkananon, M. Wald, L. Gilbert
}

\begin{abstract}
This paper focuses on the development and validation of a general interaction framework to help design technology to support communication between people and improve interactions between people, technology and objects, particularly in complex situations. A review of existing interaction frameworks shows that none of them help technology designers and developers to consider all of the possible interactions that occur at the same time and in the same place. The main and sub-components of the framework are described and explained and examples are given for each type of interaction. The framework was successfully validated by three designer experts and three accessibility experts. The designer experts focused on the main and subcomponents of the framework while accessibility experts focused on the accessibility aspects. As a result of the comments from the experts some changes to the framework components will be made. Work is now in progress to provide designers with a method to apply the framework to create technology solutions to complex communication and interaction problems and situations.
\end{abstract}

Index Terms - Interaction, framework, technology, design

\section{INTRODUCTION}

A s information and communication technology has become more important in society, many researchers have been concerned with how to use technology to support communication between people and improve interactions between people, technology and objects [1-8]. There has, however, been no framework that has helped technology designers and developers to consider all of the possible interactions that occur at the same time and in the same place although there have been projects concerned with how to use technology to support some of these interactions. For example, artefact-mediated-communication has been used to support cooperative work $[2 ; 3 ; 9 ; 20]$, a mobile digital guidebook has been used to enhance visitors' interaction with physical objects in museums [11; 19] and mobile devices have been used as mediators for the interaction with a physical object using QR codes, RFID tags and NFC tags [5; 10]. Many publications and projects in human computer interaction (HCI) focus on using technologies as a tool to enhance experiences: in the same place but at a different time (e.g. using systems for supporting group learning such as notice boards, questions and answers, electronic debates and collaborative learning [11]); in a different place but at the same time (e.g. using a Synchronous Communication Tool such as video conferencing, instant messaging and online chats to interact

Manuscript received May 11, 2013

K. Angkananon is with University of Southampton SO171BJ, UK (phone: +44 7522084233; e-mail: ka3e10@ecs.soton.ac.uk).

M. Wald is with University of Southampton SO171BJ, UK (e-mail: mw@ecs.soton.ac.uk).

L. Gilbert is with University of Southampton SO171BJ, UK (e-mail: lg3@ecs.soton.ac.uk). with learners to improve their communication with the Instructor [12]); and in a different place at a different time (e.g. using blended learning, students can access e-learning in order to learn in a different place at a different time [13]). This paper focuses on the development of a general interaction framework adapted from and extending the work of Dix [14] and Gaines [15] to help design technology to support communication between people and improve interactions between people, technology and objects, particularly in complex situations. The paper is structured as follows. Section II reviews previous research on interaction frameworks, section III explains the Technology Enhanced Interaction Framework (TEIF), section IV summarises the results of an expert validation of the TEIF and section $V$ describes the future work taking place to enable the framework to help developers design technology to enhance face-to-face interaction in the same time and the same place.

\section{REVIEW OF INTERACTION FRAMEWORKS}

Table I summarises a review of interaction frameworks and shows that many frameworks focus on people to people communication in the same time and at the same place but not using technology to enhance communication. Some frameworks address many interactions between humans and computers [3; 6]. A framework for Computer Supported Cooperative Work [14] seems to address some of the possible interactions but misses out some important interactions in the same time and at the same place situations such as people using technology to interact with real objects. In Dix's framework, the participants communicate with other participants in what is called "direct communication". Furthermore, the participants also interact with artefacts (manmade technology tools) by "controlling" or "acting". Sometimes an artefact is shared between the participants; in this case, the artefact is not only the subject of communication but can become a medium of communication, called "feedthrough". In communication about work and the artefacts of work, various means are used to refer to particular artefacts, and Dix terms this “deixis", as shown in Fig. 1. No current framework addresses all of the interactions identified in Table I. The TEIF addresses this, as explained in the next section.

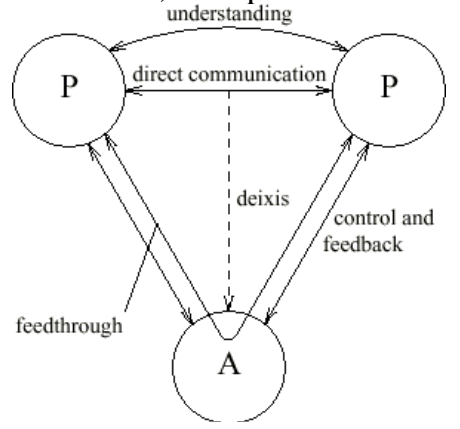


Fig. 1 Computer Supported Cooperative Work - A framework [19]

TABLE I Summarising a review of frameworks of interactions

\begin{tabular}{|c|c|c|c|c|c|c|c|c|c|c|c|c|c|c|c|c|c|c|c|}
\hline & 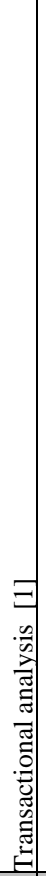 & 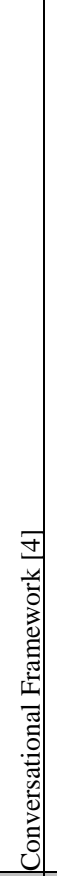 & 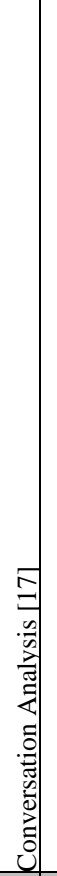 & 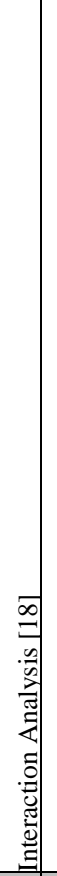 & 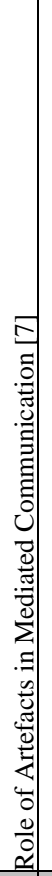 & 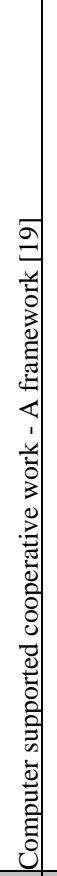 & 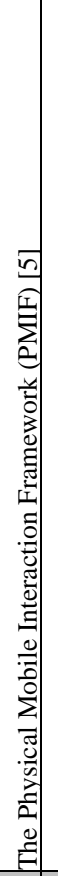 & 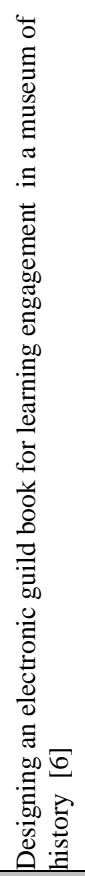 & 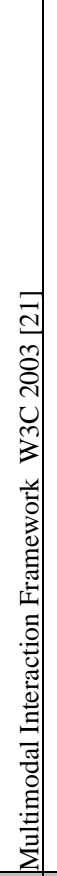 & 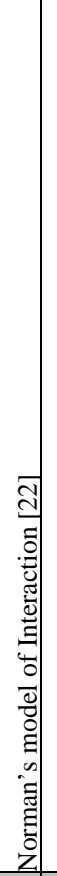 & 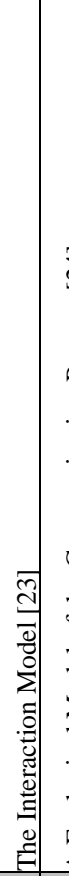 & 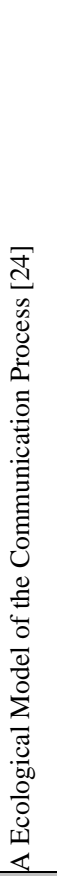 & 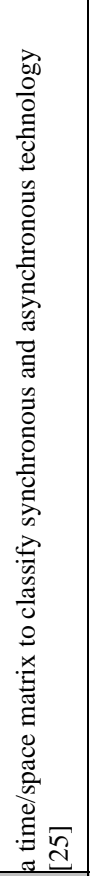 & 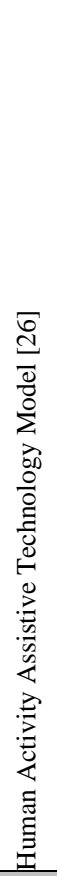 & 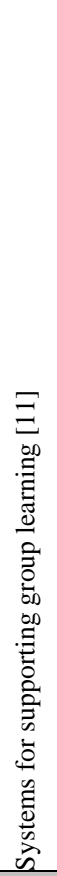 & 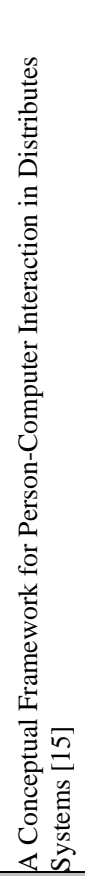 & 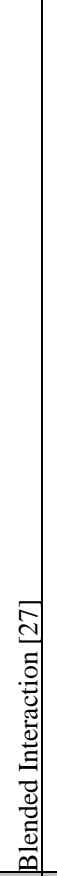 & 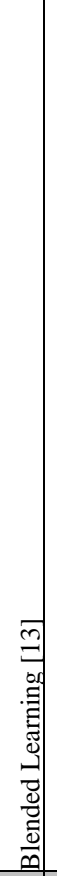 & 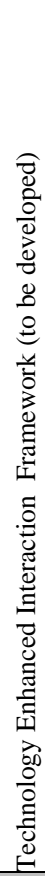 \\
\hline \multicolumn{20}{|l|}{ Direct Communication } \\
\hline People-People (P-P) & $\checkmark$ & $\checkmark$ & $\checkmark$ & $\checkmark$ & & $\checkmark$ & & & & & & $\checkmark$ & & & & & & $\checkmark$ & $\checkmark$ \\
\hline \multicolumn{20}{|l|}{ Interactions } \\
\hline People-Technology (P-T) & & & & & & & $\checkmark$ & $\checkmark$ & $\checkmark$ & $\checkmark$ & $\checkmark$ & & & $\checkmark$ & $\checkmark$ & $\checkmark$ & $\checkmark$ & $\checkmark$ & $\checkmark$ \\
\hline People-Object (P-O) & & & & & & & & & & & & & & & & & & & $\checkmark$ \\
\hline $\begin{array}{l}\text { People-technology-people } \\
\text { (P-T-P) }\end{array}$ & & & & & $\checkmark$ & $\checkmark$ & $\checkmark$ & $\checkmark$ & & & & & $\checkmark$ & & $\checkmark$ & & $\checkmark$ & $\checkmark$ & $\checkmark$ \\
\hline $\begin{array}{l}\text { People-technology-object } \\
\text { (P-T-O) }\end{array}$ & & & & & & & & $\checkmark$ & & & & & & & & & $\checkmark$ & & $\checkmark$ \\
\hline \multicolumn{20}{|l|}{ Role of interaction } \\
\hline Presenter-Audience & & & & & & & & & & & & & & & & & & & $\checkmark$ \\
\hline Sender-Receiver & & & & & & & & & & & & & & $\checkmark$ & & $\checkmark$ & $\checkmark$ & & $\checkmark$ \\
\hline Teacher-Student & & $\checkmark$ & & $\checkmark$ & & & & & & & & & & & & & & & $\checkmark$ \\
\hline Consumer-creator & & & & & & & & & & & & $\checkmark$ & & & & & & & $\checkmark$ \\
\hline Speaker-Audience & & & & & & & & $\checkmark$ & & & & & $\checkmark$ & & & & & & $\checkmark$ \\
\hline User-system & & & & & $\checkmark$ & & & & $\checkmark$ & $\checkmark$ & $\checkmark$ & & & $\checkmark$ & $\checkmark$ & $\checkmark$ & $\checkmark$ & $\checkmark$ & $\checkmark$ \\
\hline Peer-peer & & & & & & $\checkmark$ & $\checkmark$ & & & & & & & & $\checkmark$ & & & & $\checkmark$ \\
\hline No role & $\checkmark$ & & $\checkmark$ & & & & $\checkmark$ & & & & & & & & & & & & $\checkmark$ \\
\hline \multicolumn{20}{|l|}{ Space/Time } \\
\hline Same place/same time & $\checkmark$ & $\checkmark$ & $\checkmark$ & $\checkmark$ & $\checkmark$ & $\checkmark$ & $\checkmark$ & $\checkmark$ & & $\checkmark$ & \begin{tabular}{l|l}
$\checkmark$ & $\checkmark$
\end{tabular} & $\checkmark$ & $\checkmark$ & $\checkmark$ & & $\checkmark$ & $\checkmark$ & $\checkmark$ & $\checkmark$ \\
\hline $\begin{array}{l}\text { Same place/ } \\
\text { different time }\end{array}$ & & & & & & & & & $\checkmark$ & & & & $\checkmark$ & & $\checkmark$ & & & $\checkmark$ & $\checkmark$ \\
\hline $\begin{array}{l}\text { Same time/ } \\
\text { different place }\end{array}$ & & & & & & & & & $\checkmark$ & & & & $\checkmark$ & & & & & $\checkmark$ & $\checkmark$ \\
\hline $\begin{array}{l}\text { Different time/ } \\
\text { different place }\end{array}$ & & & & & & & & & $\checkmark$ & & & & $\checkmark$ & & & & & $\checkmark$ & $\checkmark$ \\
\hline \multicolumn{20}{|l|}{ Technology enhancement } \\
\hline Using technologies & & & & & $\checkmark$ & $\checkmark$ & $\checkmark$ & $\checkmark$ & $\checkmark$ & $\checkmark$ & $\checkmark$ & & $\checkmark$ & $\checkmark$ & & $\checkmark$ & $\checkmark$ & $\checkmark$ & $\checkmark$ \\
\hline Without technology & $\checkmark$ & $\checkmark$ & $\checkmark$ & $\checkmark$ & & & & & & & & $\checkmark$ & & & & & & & $\checkmark$ \\
\hline \multicolumn{20}{|l|}{ Accessibility } \\
\hline Consider accessibility & & & & & & & & & & & & & & $\checkmark$ & & & & & $\checkmark$ \\
\hline
\end{tabular}




\section{TECHNOLOGY ENHANCED INTERACTION FRAMEWORK}

The TEIF supports the design of technology enhanced interactions by developers and designers.

\section{A. Terminology}

- Communication is the process of passing information from one person to another [16].

- Technology is a tool that helps people achieve their purpose.

- People means anyone involved in direct communication or interaction with an object, technology, or other people.

- Object is anything that is not a technology or a person involved in communication or interaction.

- Interactions can be between people and objects (P-O) or people and technology (P-T). People can also use technology to mediate interaction with people (P-T-P) or objects (P-T-O).

\section{B. Main components}

There are seven main components in the TEIF as shown in Table II. People can have roles, abilities, and disabilities. The components "Object" and "Technology" are used in order to extend Dix's framework to show any type of interaction. Objects are defined as having three sub-components: dimensions, properties, and content. Technology has a cost and can be electronic or non-electronic, online or off-line, and mobile or non-mobile. Furthermore, it may or may not have stored content and may additionally have an interface and be an application or provide a service. Interactions and communication are classified into three groups:

1) Direct Communication: People to People (P-P) People in one way or two way communication with people.

2) Direct Interaction: People to Technology $(P-T)$ People can control technology and may also be able to use it to store or retrieve information; People to Objects (P-O) People can control objects and retrieve information from objects.

3) Technology Mediated Interaction: People to Technology to People (P-T-P) -Technology can mediate communication between people; People to Technology to Objects (P-T-O) - People can control objects with Technology and may also be enabled to use objects to store and retrieve information.

Time and Place can be divided into four categories [24]: same time and same place, different time but same place, same time but different place, and different place and different time. Context can include factors and constraints such as location, signal quality, background noise, and weather conditions.

The role played by the interactions and communication may be classified into one of six interaction layers, adapted from Gaines [15] as shown by the example of pressing of the letter ' $h$ ' on the keyboard when typing "hello" as a greeting when sending a text message:

- Cultural layer includes countries, tradition, language, and gesture (e.g. hello is greeting used in the culture).
- Intentionality layer involves understanding, purpose and benefit (e.g. greeting).

- Knowledge layer involves facts, concepts, and principle [16] (e.g. how to spell the word "hello".)

- Action layer involves actions and procedures [27] (e.g. pressing key ' $h$ ').

- Expression layer describes how actions are carried out (e.g. pressing the correct key).

- Physical layer is the lowest layer at which people interact with the physical world (e.g. button is depressed sending letter code to the application).

\section{Architecture of the TEIF}

The overall architecture of the TEIF involves people, technology and objects (Fig. 2). The general framework covers the use of any technology, which may or may not be electronic; the main difference is that electronic technology can store information. The TEIF extends Dix's framework [14] for computer supported cooperative work (Fig. 1) to include interaction with objects. The TEIF involves interactions from people to people (P-P), people to objects ( $\mathrm{P}$ $\mathrm{O}$ ), people to technology (P-T), people to technology to people (P-T-P) and people to technology to objects (P-T-O) as follows:

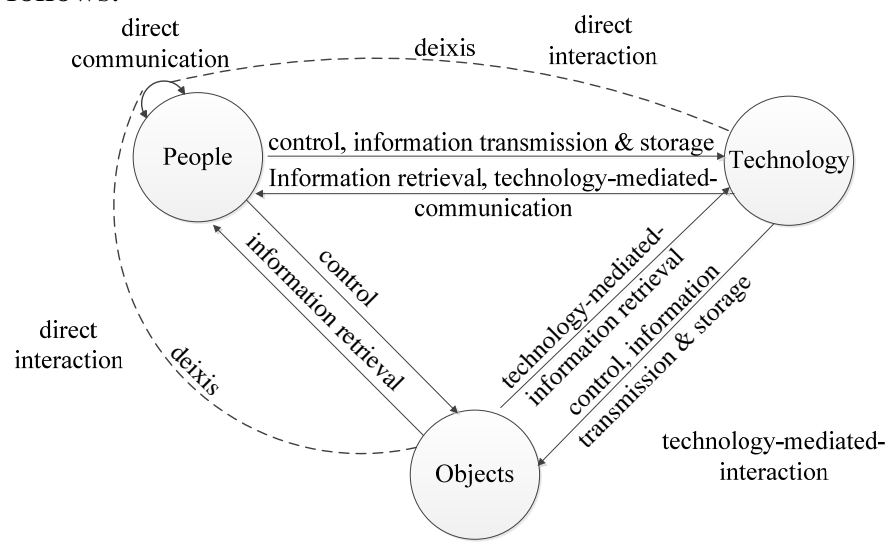

Fig. 2 The TEIF extended from Dix [7]

\section{1) Direct communication}

a)

People to People (P-P)

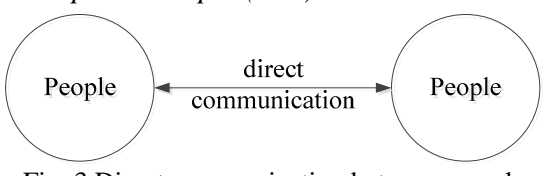

Fig. 3 Direct communication between people

The communication between people and people (Fig. 3) is a complex subject [14]. Bern [1] identified three roles of parent, adult, and child in his theory of Transactional Analysis. The conversational framework developed by Laurillard [4] describes how the roles of teachers and students interact in the learning and teaching process. Apart from a role, people have abilities or disabilities which can affect their use of technology or understanding of language and which can lead to communication breakdown. In direct communication people may refer to particular objects and technology - this is known as deixis [14]. An example of direct communication between 
GSTF Journal on Computing (JoC) Vol.3 No.2, July 2013

TABLE II Main Component of TEIF

\begin{tabular}{|c|c|c|}
\hline \multirow{2}{*}{$\begin{array}{c}\text { Main } \\
\text { Component }\end{array}$} & \multicolumn{2}{|r|}{ Main and Sub-Component of Technology Enhanced Interaction Framework } \\
\hline & $\begin{array}{c}\text { Sub- } \\
\text { component }\end{array}$ & Example \\
\hline \multirow{2}{*}{ People } & Role & $\begin{array}{l}\text { A person has a role when communicating with others (e.g. presenter, audience, peer). Roles } \\
\text { normally come in pairs such as speaker and audience (e.g. teacher and student or owner and } \\
\text { visitor) and peer to peer (e.g. student and student or visitor and visitor). }\end{array}$ \\
\hline & $\begin{array}{l}\text { Ability/ } \\
\text { Disability }\end{array}$ & $\begin{array}{l}\text { People have abilities and disabilities which can affect their use of technology or understanding of } \\
\text { language and which can lead to communication breakdown (e.g. physical, sensory, language, } \\
\text { culture, communication, Information Technology (IT)). }\end{array}$ \\
\hline \multirow{3}{*}{ Objects } & Dimension & $\begin{array}{l}\text { Objects have } 2 \text { dimensions (2D) or } 3 \text { dimensions (3D), and a 3D object may have a 2D } \\
\text { representation. }\end{array}$ \\
\hline & Property & Objects have colour, shape and size. \\
\hline & Content & $\begin{array}{l}\text { Objects have content which is human readable (text, pictures) and machine readable (QR code, } \\
\text { AR tag, barcode, RFID tag, NFC). }\end{array}$ \\
\hline \multirow{5}{*}{ Technology } & Electronic & $\begin{array}{l}\text { Electronic technology has stored information, is online (e.g. internet, phone network) or offline } \\
\text { (e.g. not connected to the internet or phone network), and is mobile (e.g. smartphone) or non- } \\
\text { mobile (e.g. desktop computer). }\end{array}$ \\
\hline & Non-electronic & $\begin{array}{l}\text { Non-electronic technology is used to store information in objects (e.g. writing with a pen on } \\
\text { paper) and is mobile (e.g. pen) or non-mobile (e.g. full-size desktop typewriter). }\end{array}$ \\
\hline & User Interface & People interact with technology through its user interface (e.g. touch screen, keyboard). \\
\hline & $\begin{array}{l}\text { Application } \\
\text { or Service }\end{array}$ & Electronic technology is an application (e.g. dictionary) or a service (e.g. weather forecast). \\
\hline & Cost & Technology has cost (e.g. of hardware, software, maintenance). \\
\hline \multirow{5}{*}{$\begin{array}{l}\text { Interactions and } \\
\text { Communication }\end{array}$} & $\begin{array}{l}\text { People-People } \\
\text { (P-P) }\end{array}$ & $\begin{array}{l}\text { People communicate verbally (speak, listen, ask, answer) and non-verbally (lip-read, smile, touch, } \\
\text { sign, gesture, nod). When communicating, people may refer (speak or point) to particular objects } \\
\text { or technology - this is known as deixis. }\end{array}$ \\
\hline & $\begin{array}{l}\text { People-Objects } \\
(\mathrm{P}-\mathrm{O})\end{array}$ & $\begin{array}{l}\text { People interact with objects for two main purposes: controlling (e.g. touch, hold or move), and } \\
\text { retrieving information (e.g. look, listen, read, in order to get information or construct personal } \\
\text { understanding and knowledge). }\end{array}$ \\
\hline & $\begin{array}{l}\text { People- } \\
\text { Technology } \\
\text { (P-T) }\end{array}$ & $\begin{array}{l}\text { People control technology (e.g. hold, move, use, type, scan, make image, press, swipe) and } \\
\text { transmit and store information (e.g. send, save, store, search, retrieve). }\end{array}$ \\
\hline & $\begin{array}{l}\text { People- } \\
\text { Technology- } \\
\text { People (P-T-P) }\end{array}$ & $\begin{array}{l}\text { People use technology to transmit information to assist communication with (e.g. send sms, mms, } \\
\text { email, chat, instant message) other people. }\end{array}$ \\
\hline & $\begin{array}{l}\text { People- } \\
\text { Technology } \\
\text {-Objects(P-T- } \\
\text { O) }\end{array}$ & $\begin{array}{l}\text { People use technology (e.g. point, move, hold, scan QR codes, scan AR tag, use camera, use } \\
\text { compass) to transmit, store, and retrieve information (send, save, store, search, retrieve) to, in, and } \\
\text { from objects. }\end{array}$ \\
\hline \multirow{2}{*}{ Time/Place } & Place & \multirow{2}{*}{$\begin{array}{l}\text { Same and different time and place yield four categories: same time (ST) and same place (SP), } \\
\text { different time (DT) and same place (SP), different time (DT) and different place (DP), same time } \\
\text { (ST) but different place (DP). }\end{array}$} \\
\hline & Time & \\
\hline \multirow{5}{*}{ Context } & Location & $\begin{array}{l}\text { Location affects the use of technology (e.g. indoors, outdoors). For example GPS does not work } \\
\text { well indoors. }\end{array}$ \\
\hline & $\begin{array}{l}\text { Weather } \\
\text { Condition }\end{array}$ & $\begin{array}{l}\text { Weather condition may affect the use of technology (e.g. rainy, cloudy, sunny, windy, hot, cold, } \\
\text { dry, wet). For example, the mobile phone screen doesn't work well in sunshine. }\end{array}$ \\
\hline & $\begin{array}{l}\text { Signal Type } \\
\text { and Quality }\end{array}$ & Signal type can affect the quality of electronic technology (e.g. broadband, GPS, 3G, 4G). \\
\hline & $\begin{array}{l}\text { Background } \\
\text { Noise }\end{array}$ & $\begin{array}{l}\text { Background noise can affect the communication particularly for hearing impaired people (e.g. } \\
\text { background music, crowded situation). }\end{array}$ \\
\hline & Lighting & Light can affect the interaction (e.g. Inadequate light, too bright). \\
\hline \multirow{6}{*}{$\begin{array}{l}\text { Interaction } \\
\text { Layer }\end{array}$} & Culture & $\begin{array}{l}\text { Cultural layer includes countries, traditional, language and gesture (e.g. "hello" is a normal } \\
\text { greeting used in the culture). }\end{array}$ \\
\hline & Intentionality & Intention layer involves understanding, purpose and benefit (e.g. the intent is a greeting). \\
\hline & Knowledge & $\begin{array}{l}\text { Knowledge layer involves facts, concepts, procedures, and principles (e.g. how to spell the word } \\
\text { "hello"). }\end{array}$ \\
\hline & Action & $\begin{array}{l}\text { Action layer involves actions and behaviours (e.g. pressing the correct key and not hitting } \\
\text { neighbouring keys). }\end{array}$ \\
\hline & Expression & $\begin{array}{l}\text { Expression layer describes how actions are carried out (e.g. whether action is correct, accurate, } \\
\text { prompt). }\end{array}$ \\
\hline & Physical & $\begin{array}{l}\text { Physical layer is the lowest layer at which people interact with the physical world (e.g. the button } \\
\text { is depressed and so sends the electronic code for the letter to the application). }\end{array}$ \\
\hline
\end{tabular}


people is in a classroom at school; the teacher's role is characteristically to provide information, show examples, ask questions, and provide feedback. A student characteristically undertakes learning activities such as listening, asking and answering questions. However, there may be students who are deaf or blind, who have difficulty in learning or using technology, or international students who have difficulties in understanding a non-native language of instruction.

\section{2) Direct Interaction}

a)

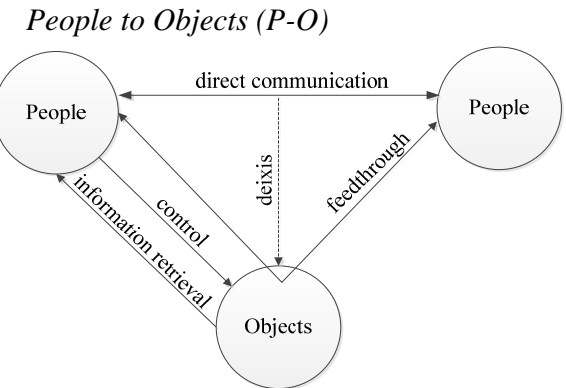

Fig. 4 Interaction between people and objects

In direct interaction, people interact with objects (Fig. 4) by pointing, looking, or touching (P-O). There are two main purposes in the interaction between people and objects: control, and information retrieval. People control objects by moving, or holding them, and can receive information by looking at or touching them, perhaps while being guided by other people drawing attention to them. For example, a museum guide may point at an exhibit (deixis) when explaining its history to visitors. Blind visitors can touch the object to get information such as shape, size, and weight. In direct interaction, when a person acts upon an object (e.g. moving a piano), the other people may feel the effect of the action, which is called "feedthrough" in Dix's framework [2].

b)

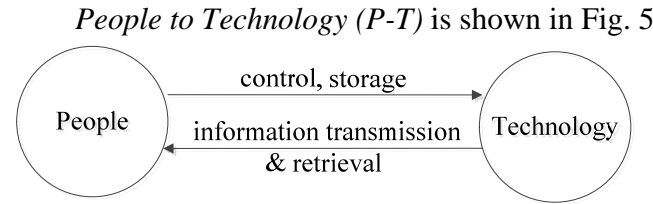

Fig. 5 The interaction between people and technology

People can control technology (e.g. touch screen) and store information (e.g. save) into technology. Moreover, people can retrieve information from technology (e.g. scan QR codes)

\section{3) Technology supported communication}

a)

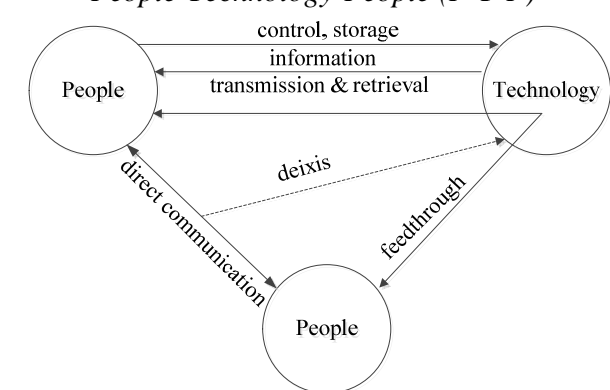

Fig. 6 The interaction between people to technology to people
Communication between people and people using technology mediation usually aims to improve that communication (Fig. 6). An example is people using their smart phones to communicate to each other by sending SMS or MMS messages, calling, sending email, sharing information through Bluetooth, or text chatting through mobile applications.

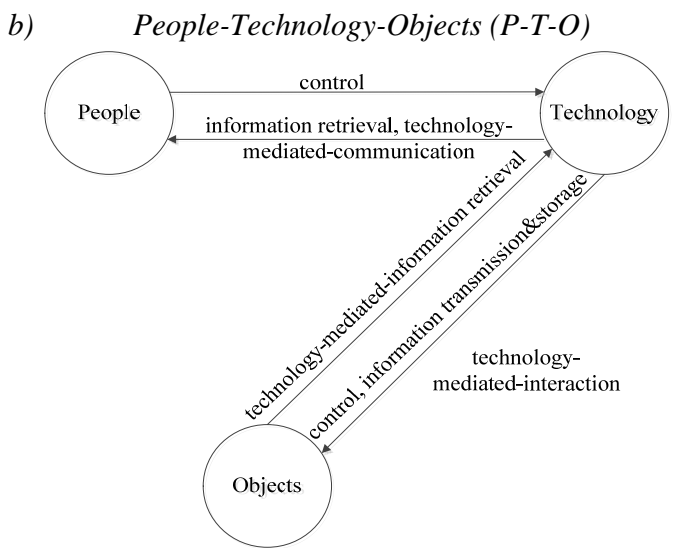

Fig. 7 The interaction between people to technology to objects

The interaction between people and objects through technology mediated information retrieval (Fig. 7) is illustrated by people using (controlling) their mobile phones to take photos of a building or to scan QR codes on the building.

\section{EXPERT VALIDATION AND REVIEW}

Validation and review of the framework was piloted by one experienced accessibility expert and two experienced designers/ developers experts and undertaken using an online system and interviews before the next step of engaging with the users (technology designers). Based on their responses changes were made to improve the questions, response times and layout. The pilot study participants were shown all these changes and confirmed that they were satisfied with them. The validation of the TEIF was considered by two groups of experts: designer/developer experts and accessibility experts. The designer experts focused on the main and sub-components while accessibility experts focused on checking the accessibility aspects. In addition the opportunity arose to discuss the TEIF with a professor who is world renowned in the HCI field. If the majority of experts answered "Yes" to the questions this was considered as a successful validation. The TEIF Framework was successfully validated by the experts (Table III) but as a result of the comments from the three designer experts and the expert professor the following changes to the framework components will be made.

TABLE III Experts Validating TEIF

\begin{tabular}{|l|l|l|}
\hline Questions & $\begin{array}{l}\text { \% of experts } \\
\text { answering } \\
\text { "Yes” }\end{array}$ & $\begin{array}{l}\text { Successful } \\
\text { validation }\end{array}$ \\
\hline 1. Are the instructions clear? & $67 \%$ & Yes \\
\hline $\begin{array}{l}\text { 3. Are the examples and } \\
\text { explanations clear? }\end{array}$ & $100 \%$ & Yes \\
\hline $\begin{array}{l}\text { 5. Do you agree with the main } \\
\text { and sub-components of the } \\
\text { framework? }\end{array}$ & $100 \%$ & Yes \\
\hline
\end{tabular}


The "Objects" component: one expert suggested finding a better word than objects but it has not been possible to find a better word and so the definition and meaning of the word in the TEIF context will be explained in more detail. The TEIF has a consistent and clearly defined meaning of the word "Objects" but only a brief explanation was provided for the experts because of time limitation.

The "Weather Condition" sub-component: one expert found this "Oddly Specific" and so more examples of how weather condition could affect technology interactions will be provided.

The "Examples" sub-heading: an expert suggested it was unclear what the examples were and what were the explanations and so the sub-heading will be changed to "Explanations and examples".

People being aware of other interactions: this aspect will be added as a sub-component to the context component as the professor suggested this might be something worth considering in the TEIF (e.g. between other people or between other people and technology or other people and objects).

Identity of an object: the identity of an object will be added to the sub-component "Property" as an example as suggested by the professor.

User Perception: an explanation will be provided that as pointed out by the professor, users may have the perception that technology (e.g. a robotic device triggered by the person walking past it) talking to them is a "Technology to People" interaction (T-P) whereas the TEIF categorises it as a "People - Technology-People” interaction (P-T-P).

Framework components as index for case based solutions: the Professor agreed that the framework components could be useful as an index for case based solutions. This aspect will be considered for the user evaluation.

Instructions: the majority of experts suggested providing more information about the purpose of the framework. This participant information was provided through the invitation email but some of the experts appear to have not read this carefully and so the information will be also provided in the start page of the online survey.

\section{CONCLUSION AND FUTURE WORK}

The TEIF addresses the issue that, until now, there has been no framework to support technology designers and developers in considering all of the possible interactions that might occur at the same time and in the same place. The Framework has been validated and reviewed by experts and work is now in progress to provide technology designers with an easy to use tool that helps them apply the framework to create technology solutions to complex communication and interaction problems and situations.

\section{REFERENCES}

[1] BERNE, E. 1964. Games People Play - The Basic Hand Book of Transactional Analysis, New York, Ballantine Books.

[2] DIX, A. 1997. Challenges for Cooperative Work on the Web: An Analytical Approach. Computer Supported Cooperative Work (CSCW), 6, 135-156.
[3] DIX, A., FINLAY, J., ABOWD, D. G. \& BEALE, R. 2004. HumanComputer Interaction, Madrid, Spain, Prentice Hall.

[4] LAURILLARD, D. 1993. Rethinking University Teaching: a framework for the effective use of educational technology, London, Routledge.

[5] RUKZIO, E. A. B., GREGOR AND WETZSTEIN, SERGEJ 2008. The Physical Mobile Interaction Framework (PMIF). Technical Report LMU-MI-2008-2.

[6] SUNG, Y.-T., CHANG, K.-E., HOU, H.-T. \& CHEN, P.-F. 2010. Designing an electronic guidebook for learning engagement in a museum of history. Computers in Human Behavior, 26, 74-83.

[7] VYAS, D., DIX, A. \& NIJHOLT, A. 2008. Role of Artefacts in Mediated Communication. CHI 2008. Florence, Italy: ACM SIGCHI.

[8] HSI, S. \& FAIT, H. 2005. RFID enhances visitors' museum experience at the Exploratorium. Commun. ACM, 48, 60-65.

[9] DIX, A. 1995. Cooperation without (reliable) communication: Interfaces for mobile applications. Distributed Systems Engineering, 2, 171.

[10] BROLL, G., SIORPAES, S., RUKZIO, E., PAOLUCCI, M., HAMARD, J., WAGNER, M. \& SCHMIDT, A. Supporting Mobile Service Usage through Physical Mobile Interaction. Pervasive Computing and Communications, 2007. PerCom '07. Fifth Annual IEEE International Conference on, 19-23 March 2007 2007. 262-271.

[11] LEE, D. S., ARMiTAGE, S., GROVES, P. \& STEPHENS, C. 2009. Systems for supporting group learning.

[12] WANG, S.-K. 2008. The Effects of a Synchronous Communication Tool (Yahoo Messenger) on Online Lerners' Sense of Community and their Multimedia Authoring Skills. Journal of Interactive Online Learning, 7.

[13] KLINK, M. 2006. The use of interaction methods in a blended learning environment. master, University of Twente.

[14] DIX, A. J. 1994. Computer supported cooperative work - a framework. Springer Verlag, 23-37.

[15] GAINES, B. R. 1988. A conceptual framework for person-computer interaction in complex systems. Systems, Man and Cybernetics, IEEE Transactions on, 18, 532-541.

[16] DAVIS, K. 1977. Human Behavior At Work, New York, McGraw-Hill Book Co.

[17] SACKS, H. 1974. An Analysis of the Course of a Joke's Telling in Conversation Cambridge, Cambridge University Press.

[18] FLANDERS, N. A. 1960. Interaction Analysis in the Classroom; A Manual for Observers, Michigan, University of Michigan.

[19] DIX, A. J. 1994. Computer supported cooperative work - a framework. In Design Issues in CSCW Eds. D. Rosenburg and C. Hutchison., Springer Verlag, 23-37.

[20] LARSON, A. J., RAMAN, T. V. \& RAGGETT, D. 2003. W3C Multimodal Interaction Framework. Available: http://www.w3.org/TR/mmi-framework/.

[21] NORMAN, D. A. \& DRAPER, S. W. 1986. User Centered System Design: New Perspectives On Human-Computer Interaction, Lawrence Erlbaum Associates, Hillsdale, N.J.

[22] ABOWD, G. D. \& BEALE, R. 1991. Users, systems and interfaces: A unifying framework for interaction. HCI'91: People and Computers, 73-87.

[23] FOULGER, D. 2004. Models of the Communication Process. Available: http://davis.foulger.info/research/unifiedModelOfCommunication.htm.

[24] ELLIS, J. R., RIDOLFI \& G. \& ZWIRNER, F. 1991. Groupware: Some issues and experiences. Communications of the ACM, 34.

[25] COOK, A. \& HUSSEY, S. 1995. Assistive Technologies: Principles and Pratice, Mosby, St. Louis, MO.

[26] JETTER, H.-C., GEYER, F., SCHWARZ, T. \& REITERER, H. 2012. Designing Collaborative Interactive Spaces. Personal and Ubiquitous Computing.

[27] MERRILL, M. D. (2008). Reflections on a four decade search for effective, efficient and engaging instruction. In M. W. Allen (Ed.), Michael Allen's 2008 e-Learning Annual (Vol. 1, pp. 141-167): Wiley Pfieffer. 


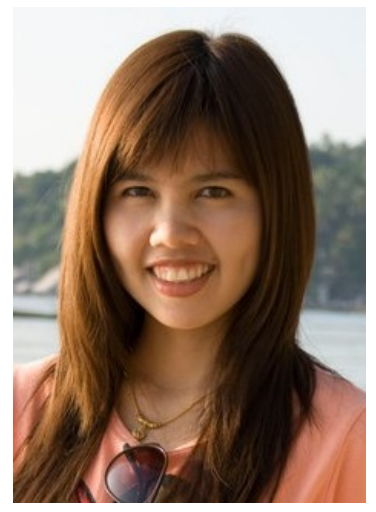

K. Angkananon is a $\mathrm{PhD}$ student in ECS Web and Internet Science (WAIS) group at the University of Southampton. Her supervisors are Dr. Mike Wald and Lester Gilbert. She is also a lecturer in the Business Computer Department of the Faculty of Management in the Suratthani Rajabhat University in Thailand.

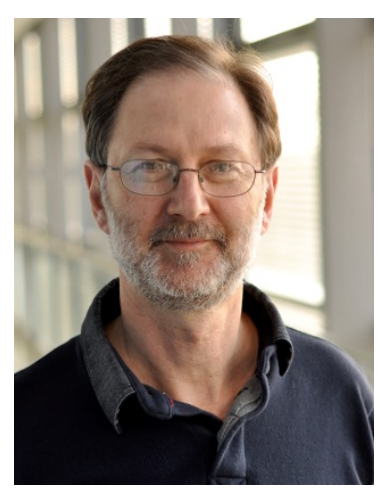

Dr M. Wald leads research into accessible technologies in WAIS and has advised organizations and universities on enhancing learning through the use of technologies. He is a founding member of the International Liberated Learning Consortium investigating how speech recognition can make teaching and learning more accessible.

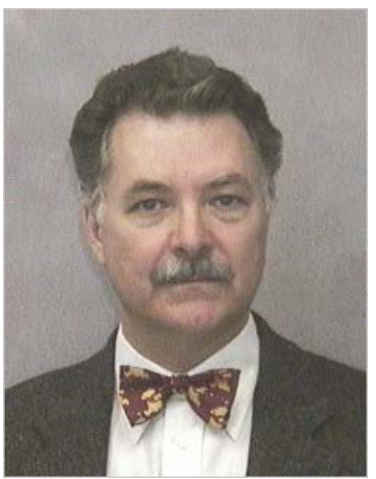

L. Gilbert lectures on e-Learning and Technology Enhanced Learning .on ECS's "IT in Organisations" degree programme, His book (co-authored with Veronica Gale) "Principles of eLearning Systems Engineering" (Chandos, 2008) integrates his practical experience of Information Systems and Multimedia and Computer Aided Instruction development. 